\title{
Puiggrós A. (2019). El pensamiento de Paulo Freire en tiempo presente. Conferencia de inauguración de la Cátedra Libre Paulo Freire de la UNLP
}

\author{
María Aprigliano \\ marilu.aprigliano@gmail.com \\ Universidad Nacional de La Plata, Argentina \\ Sabrina Larocca \\ sabri.larocca@gmail.com \\ Universidad Nacional de La Plata, Argentina
}

Cita sugerida: Aprigliano, M. y Larocca, S. (2020). [Revisión de la conferencia El pensamiento de Paulo Freire en tiempo presente por A. Puiggrós]. Archivos de Ciencias de la Educación, 14(17), e085. https://doi.org/10.24215/23468866e085

El 23 de mayo de 2019 la Facultad de Humanidades y Ciencias de la Educación de la Universidad Nacional de La Plata fue sede de la conferencia El pensamiento de Paulo Freire en tiempo presente a cargo de la Dra. Adriana Puiggrós, en el marco de la apertura de la Cátedra Paulo Freire. El encuentro contó con la presencia del Doctor Fernando Tauber, presidente de la UNLP; la Doctora Adriana Puiggrós, ex Secretaria de Educación de la Nación; el Doctor Martín Legarralde, director del Departamento de Ciencias de la Educación de la FaHCE-UNLP, y Mónica Fernández País, ex Directora de Educación Inicial de la Nación y coordinadora de la Cátedra Libre Paulo Freire.

La creación de esta cátedra cobró especial relevancia para la FaHCE porque inauguró un espacio novedoso para la producción de conocimiento y el estudio de los aportes del pedagogo Paulo Freire en clave presente. Según Adriana Puiggrós, representa una respuesta política y pedagógica muy interesante en un contexto latinoamericano donde el neoliberalismo ha puesto en marcha medidas contra la educación de nuestros pueblos. En este sentido, para la autora la gestión de Mauricio Macri en nuestro país y la de Jair Bolsonaro en Brasil han impulsado la destrucción de los lazos comunitarios y el recorte de derechos humanos fundamentales. 
La propuesta de formación que se presentó aquí es coherente con la denuncia realizada por la FaHCEUNLP en la Resolución Nro. 1242/19, ante las medidas tomadas por el gobierno brasileño que no sólo representaron un ajuste presupuestario propio del neoliberalismo sino que también se inscribieron en declaraciones tales como "entrar al Ministerio de Educación con un lanzallamas para erradicar a Paulo Freire". En dicha resolución también se denunció el retroceso en términos del derecho a la Educación Superior consagrado por las declaraciones de la Conferencia Regional de Educación Superior (CRES) de 2008 y 2018 y se expresó la solidaridad con la lucha de nuestra hermana comunidad universitaria de Brasil en defensa del derecho a la educación.

Es importante señalar que esta cátedra se integra a la Red de Cátedras Libres Paulo Freire conformada por universidades nacionales y latinoamericanas, que buscan atender la necesidad de fortalecer la mirada pedagógica a lo largo de América Latina a partir del pensamiento freireano. La integran referentes tanto a nivel nacional como internacional, provenientes de altas casas de estudio como la Universidad Nacional de La Plata, Universidad Nacional de Entre Ríos, Universidad de Buenos Aires, Facultad Latinoamericana de Ciencias Sociales, Universidad Iberoamericana de México, Universidad de París, Universidad de Essex.

En dicho evento el director del Departamento de Ciencias de la Educación, Dr. Martín Legarralde, resaltó la importancia de que "la preocupación ante el avance de la derecha en Latinoamérica y su ataque sistemático al pensamiento freireano, haya colmado de estudiantes y docentes una de las aulas más grandes de la Facultad".

La Dra. Mónica Fernández País señaló la relevancia de encontrarnos en una coyuntura compleja, donde el gobierno de Bolsonaro ejecutó la prescripción del pedagogo en Brasil. Su proyecto político acusó al Centro Paulo Freire del Movimiento de los Trabajadores Rurales Sin Tierra de Pernambuco como formador de guerrilleros, en un claro posicionamiento fascista que atenta contra la continuidad de este proyecto político pedagógico fundamental para la región. En consonancia con estas políticas, según Fernández, Argentina ejecutó durante este período una pedagogía del vaciamiento y un desguace sistemático del sistema educativo a través, por ejemplo, del desfinanciamiento de instancias de formación que tenían como objeto de estudio las pedagogías latinoamericanas y los derechos humanos, con una clara intención de eliminar el germen "de la educación popular de la formación docente”. Fernández, en este sentido, reafirmó la necesidad de seguir construyendo universidades cuya formación y práctica docente estén atravesadas por una educación freireana, para que los espacios de militancia "dejen de ser cartel para volverse aula", y que hasta en el "lugar más pequeño donde haya una práctica educativa, la educación emancipadora sea bandera”.

Por su parte, el Presidente de la UNLP, Dr. Fernando Tauber, reflexionó sobre la importancia de que esta casa de estudios sea referencia del pensamiento propio, autónomo, comprometido, crítico, popular y feminista. Reivindicó la formación de la Cátedra como una invitación a construir desde la educación como capital principal de nuestro pueblo, como política pública estatal que favorezca la inclusión. Por otro lado, presentó a la Dra. Adriana Puiggrós poniendo en valor su rol protagónico en la modificación de la ley 24.521/15, a través de la cual se establece a la Educación Superior como responsabilidad del Estado Nacional garantizando la gratuidad y la igualdad de oportunidades de acceso y permanencia a todas las instituciones del Nivel Superior. En este sentido, resaltó la importancia de ser el primer país de Latinoamérica en tener educación universitaria pública, gratuita, irrestricta y autónoma, principios que históricamente ha defendido la UNLP.

Podemos señalar que la pertinencia del discurso de Adriana Puiggrós en esta presentación reside en su amplio recorrido como docente, investigadora y funcionaria en la educación en Argentina. ${ }^{1}$ Además, destacamos su rol activo en el campo de las políticas públicas relacionadas a experiencias alternativas en educación, que recuperan la visión del Estado como garante del ejercicio pleno del derecho a la educación, con reconocimientos como el título Honoris Causa de la UNLP y la Orden Andrés Bello, entregada por el Gobierno de Venezuela en 2005.

La decisión de retomar el legado de Paulo Freire se enmarca en la riqueza de su vida y obra. Freire nació en 1921 en una de las regiones más empobrecidas del nordeste de Brasil. Su pensamiento fue atravesado por 
los procesos de transformación política que allí se vivían y acompañado por lecturas en torno a la renovación de la Iglesia Católica y los desarrollos marxistas. El autor expresa un aporte categórico al pensamiento pedagógico latinoamericano con un potencial transformador de las prácticas educativas. Recupera en sus trabajos, comprometido con su tiempo y la gente de su tierra, las voces silenciadas de los oprimidos, como él los llamaba. En el campo pedagógico ayudó a trazar un nuevo camino a partir de una propuesta que modificó de manera radical la relación educador-educando. Como plantea en una de sus obras más importantes, Pedagogía del oprimido (1968), la pedagogía debe ser elaborada no para el pueblo sino con el pueblo, en lucha permanente por la recuperación de su humanidad. Una pedagogía que haga de la opresión y sus causas objeto de reflexión de los oprimidos, de lo que resultará el compromiso necesario para su lucha por la liberación, en la cual esta pedagogía se hará y rehará (Freire, 1970).

En el transcurso de la conferencia, Puiggrós hizo hincapié en tres necesidades fundamentales que debemos atender quienes estamos vinculadas y vinculados con la educación. Expresó que la primera enseñanza que debemos retomar del pensamiento freireano es la exigencia que significa comenzar a historizar nuestra matriz pedagógica, para construir saberes desde la línea de pensamiento que nos habita en Latinoamérica.

En consecuencia, realizó un recorrido histórico que diagramó en tres momentos para mostrar la configuración del pensamiento pedagógico de nuestro sur. Un primer momento donde analizó su configuración histórica, un segundo momento donde situó a Freire en su tiempo histórico y coyuntural y, finalmente, a partir de esta historización, propuso algunas categorías freireanas para pensarlo en presente.

Comenzó delimitando momentos donde el pensamiento latinoamericano fue fragmentado, como por ejemplo durante el Tratado de Tordesillas que separó a las tierras de la corona Española y Portuguesa; la Guerra de la Triple Alianza y, avanzado el siglo XX, la Doctrina Monroe que colocó a los países de América Latina "en el patio de atrás" de los Estados Unidos.

En su libro La educación popular en América Latina: Orígenes, polémicas y perspectivas (2016), Puiggrós continúa delimitando una línea de pensadores que aportaron a la construcción conceptual de la unidad latinoamericana, a partir del estudio de los posicionamientos que una diversidad de autoras y autores han tenido contra la forma de construcción de la sociedad capitalista que vincula saber y poder. En esta obra la autora retoma la idea de que la producción pedagógica latinoamericana ha vivido la reproducción, supervivencia y transformación cultural como problemáticas propias, entendiendo que en la educación libramos una lucha en la que intentamos penetrar al discurso pedagógico colonizador desde aquellos sentidos provenientes de la realidad latinoamericana.

Con respecto a Freire, como intelectual del siglo XX, en la conferencia Puiggrós recuperó varios aspectos históricos que configuraron la matriz de sus ideas. Lo situó como un pensador coetáneo del Che Guevara que, ya en el período previo a las dictaduras cívico-militares, vio la necesidad de consolidar un cambio cultural profundo. Aseguró que fue en contextos de exilios forzados, de trabajo internacional, de compartir su experiencia brasileña con varios países del mundo, que pudo construir una dimensión universal.

Desde la construcción del momento de época de Freire, Puiggrós hizo mención a varias categorías que nos permiten aprehender el pensamiento freireano para retomarlo en el siglo XXI y proyectar nuevas soluciones, nuevas salidas, desde el aula, en nuestras prácticas educativas.

La primera categoría que retomó es la de educación bancaria. Para pensar este punto, mencionó que Freire traza una línea histórica que nos permite analizar el carácter colonizador de todos los sistemas educativos modernos y a partir del cual se edificó en nuestras pedagogías una colonización del pensamiento, que implicó un vínculo pedagógico unilateral sin lugar para el diálogo o para el intercambio entre diversas culturas y lenguas. Para Freire, y para la filosofía de la educación crítica, es preciso construir otra racionalidad en la cultura occidental, donde el diálogo en el vínculo pedagógico sea relacional, en tanto nadie tiene la iniciativa absoluta.

Otro aspecto relevante del pensamiento del pedagogo que retomó Puiggrós en su conferencia es la relación que establece entre educación y política. Resalta la politicidad de la educación y el lugar de la conciencia en 
el vínculo pedagógico. Así, la construcción de la razón crítica se configura como el propósito del vínculo pedagógico, cuya ecuación posibilita tomar conciencia del mundo, del lugar que ocupamos en el mundo y, por lo tanto, del conjunto de saberes que nos constituyen, es decir, nos permite concienciarnos.

En base a ese recorrido teórico, Puiggrós resaltó la necesidad de abandonar la falta de imaginación y la construcción a la que nos condenan estas formas de racionalidad occidental. Por ello, la invitación a inscribirnos en una línea de pensamiento latinoamericano, a saber de dónde proviene lo que pensamos, a encontrar articulaciones y a definir en qué historia queremos inscribirnos. Este proceso implica traducir las enseñanzas que nos brindó Freire y nos permite construir un vínculo pedagógico anclado en suelo latinoamericano, que reconozca nuestra pluralidad cultural, nuestras lenguas y nuestra historia. En La escuela, plataforma de la patria (2019), Puiggrós propone pensar a la escuela como último espacio de la Nación para protegerla de la avanzada neoliberal sobre nuestra educación y soberanía. En ese mismo texto afirma que la escuela "también es una plataforma constructora de alteridades. Separa ruido de información. Produce información. Designa, divide, evalúa, valoriza, incluye, excluye, forma sujetos. Pero ningún habitante de América Latina queda fuera de su influencia, por acción o por omisión" (2018, p.116) y agrega que, reflexionando en términos históricos, "desde Simón Rodríguez en adelante, (...) necesitamos imaginar o morimos. En materia de educación no se trata solo de imaginar futuros, sino de hacer consciente la performatividad de nuestra palabra sobre esos futuros (p. 123).

Puiggrós compartió su entusiasmo ante la apertura de las actividades de la Cátedra Libre Paulo Freire porque implica construir un espacio de mucha producción, imaginación y aporte a nuestra Facultad, a la Universidad y, sin dudas, a la educación argentina y latinoamericana; en consecuencia, avanzar hacia el inédito viable. De esta manera invitó a "superar la tremenda sugestión de pensar que no es posible y lograr que el conjunto del pueblo piense que sí lo es. Los educadores de la tradición latinoamericanista tenemos que asumir un rol fuerte en esa tarea porque sabemos apostar a lo probable y también a las utopías; aunque no se trate con seguridad de lo posible, porque esa es nuestra identidad, somos idealistas que lanzamos flechas al futuro." (Puiggrós, 2018, p.17).

A más de un año de la realización del panel, alzamos como bandera la invitación de la Universidad Nacional de La Plata, del Departamento de Ciencias de la Educación de la FaHCE y de la Cátedra Libre Paulo Freire, a construir nuevos vínculos educativos que busquen cuestionar las formas de caminar las aulas, desde los territorios, en la construcción de una realidad justa, con pleno ejercicio de nuestros derechos. Será preciso entonces, abrirnos, re-orientarnos, subvertir sentidos y preocupaciones para seguir pintándonos de pueblo.

\section{RefEREnCias}

Puiggrós, A. (2016). La educación popular en América Latina: origenes, polémicas y perspectivas. Buenos Aires: Colihue Puiggrós, A. (2019). Luchas por una democracia educativa: 1995-2018. Buenos Aires: Galerna

Puiggrós, A. (2019). La escuela, plataforma de la patria. Buenos Aires: UNIPE-CLACSO. Recuperado de http://bib lioteca.clacso.edu.ar/clacso/se/20191205024740/La-escuela.pdf

\section{Fuentes}

Resolución n ${ }^{\circ}$ 1242/19 de la Facultad de Humanidades y Ciencias de la Educación de la UNLP Repudio a la política universitaria del gobierno brasileño. Recuperado de http://www.memoria.fahce.unlp.edu.ar/normativa/no.12 1/no.121.pdf

Comunicado de la Cátedra Libre Paulo Freire en solidaridad con el Centro Paulo Freire del MST (Movimiento de los Trabajadores Rurales Sin Tierra). Recuperado de https://www.facebook.com/CatedraLibrePabloFreireUNLP /photos/a.2313287565619167/2391124607835462 
Ley de implementación efectiva de la responsabilidad del Estado en el nivel de Educación Superior $\mathrm{N}^{\circ} 24.521$. Modificación. Sancionada: octubre 28 de 2015. Promulgada: noviembre 09 de 2015. Recuperado de http://ser vicios.infoleg.gob.ar/infolegInternet/anexos/250000-254999/254825/norma.htm

\section{Notas}

1 Directora General de Cultura y Educación de la Provincia de Buenos Aires entre 2005 y 2007 y recientemente como Secretaria del Ministerio de Educación (2020). 